\title{
Adaptive selection of an incretin gene in Eurasian populations
}

\author{
Chia Lin Chang, ${ }^{1}$ James J. Cai, ${ }^{2,3}$ Chiening Lo, ${ }^{4}$ Jorge Amigo, ${ }^{5}$ Jae-II Park, ${ }^{6}$ \\ and Sheau Yu Teddy $\mathrm{Hsu}^{7,8}$
}

${ }^{1}$ Department of Obstetrics and Gynecology, Chang Gung Memorial Hospital Linkou Medical Center, Chang Gung University, Kweishan, Taoyuan 333, Taiwan; ${ }^{2}$ Department of Biology, Stanford University, Stanford, California 94305, USA; ${ }^{3}$ Department of Veterinary Integrative Biosciences, Texas A\&M University, College Station, Texas 77840, USA; ${ }^{4}$ Department of Clinical and Experimental Epilepsy, Institute of Neurology, University College London, London WC1N 3BG, United Kingdom; ${ }^{5}$ Genomic Medicine Group, University of Santiago de Compostela, CIBERER, Santiago de Compostela 15706, Spain; ${ }^{6}$ Hormone Research Center and School of Biological Sciences and Technology, Chonnam National University, Kwangju 500-712, Republic of Korea; ${ }^{7}$ Reproductive Biology and Stem Cell Research Program, Department of Obstetrics and Gynecology, Stanford University School of Medicine, Stanford, California 94305-5317, USA

\begin{abstract}
Diversities in human physiology have been partially shaped by adaptation to natural environments and changing cultures. Recent genomic analyses have revealed single nucleotide polymorphisms (SNPs) that are associated with adaptations in immune responses, obvious changes in human body forms, or adaptations to extreme climates in select human populations. Here, we report that the human GIP locus was differentially selected among human populations based on the analysis of a nonsynonymous SNP (rs2291725). Comparative and functional analyses showed that the human GIP gene encodes a cryptic glucose-dependent insulinotropic polypeptide (GIP) isoform (GIP55S or GIP55G) that encompasses the SNP and is resistant to serum degradation relative to the known mature GIP peptide. Importantly, we found that GIP55G, which is encoded by the derived allele, exhibits a higher bioactivity compared with GIP55S, which is derived from the ancestral allele. Haplotype structure analysis suggests that the derived allele at rs 2291725 arose to dominance in East Asians $~ 8100$ yr ago due to positive selection. The combined results suggested that rs2291725 represents a functional mutation and may contribute to the population genetics observation. Given that GIP signaling plays a critical role in homeostasis regulation at both the enteroinsular and enteroadipocyte axes, our study highlights the importance of understanding adaptations in energy-balance regulation in the face of the emerging diabetes and obesity epidemics.
\end{abstract}

[Supplemental material is available online at http:// www.genome.org.]

Recent studies have revealed that genetic variation underlies a variety of diversities in human physiology and pathology (Sabeti et al. 2005; Voight et al. 2006, 2010; Sulem et al. 2007; Tishkoff et al. 2007; Genovese et al. 2010; Leslie 2010; Simonson et al. 2010; Yi et al. 2010). Among the sundry forms of genetic variation, single nucleotide polymorphisms (SNPs) with high population differentiation are regarded as candidates of adaptation to recent changes in human environment and culture, and have been shown to play an important role in acquiring distinct physiological traits and susceptibility to different diseases among the populations (Barreiro and Quintana-Murci 2010; Chen et al. 2010; Gibbons 2010; Ingelsson et al. 2010; Laland et al. 2010; Luca et al. 2010; Richerson et al. 2010). Thus, the identification of causal SNPs with signatures of positive selection and underlying functional changes is crucial to a better understanding of the relationship between genomic variation and human health as well as gene-environmental interactions (Nielsen et al. 2007; Laland et al. 2010; Nei et al. 2010). To systematically analyze the contributions of genetic variation in intercellular signaling molecules to physiological diversities in humans, we studied SNPs in the coding region of 839 human polypeptide hormones and their cognate receptors for evidence of

\footnotetext{
${ }^{8}$ Corresponding author.
}

E-mail teddyhsu@stanford.edu; fax (650) 725-7102.

Article published online before print. Article and publication date are at http://www.genome.org/cgi/doi/10.1101/gr.110593.110. selection using the data from the International HapMap project phases I and II (International HapMap Project 2003; International HapMap Consortium 2007). We focused on these polypeptide ligands and receptors because they represent half of the targets of modern medicine (Drews 2000) and because the genes associated with intercellular communication or the responses to environmental factors (e.g., pathogens and food sources) have been implicated in the evolution of a variety of common traits and pathologies in humans and other vertebrates (Seminara et al. 2003; Sabeti et al. 2005; Hoekstra et al. 2006; Lalueza-Fox et al. 2007; Sulem et al. 2007; Chambers et al. 2008; Prokopenko et al. 2008; Shiao et al. 2008; Shimomura et al. 2008; Anderson et al. 2009; Topaloglu et al. 2009). Here, based on genomic and biochemical analyses, we show that variants in an incretin hormone gene, GIP, were differentially selected in human populations, and a nonsynonymous SNP, rs2291725, represents a functional mutation. Because changes in the food source represented one of the most important selection pressures during the transitions of human culture and because incretin hormones play critical roles in homeostasis maintenance at the enteroinsular and enteroadipocyte axes, future studies of potential genotype-phenotype relationships for the selected GIP variants could provide a better understanding of which and how these variants contribute to phenotypic variation in energy-balance regulation among individuals or human populations. 


\section{Results}

A nonsynonymous SNP (rs2291725) in the human glucose-dependent insulinotropic polypeptide gene exhibits high population differentiation

To investigate whether variation in the polypeptide intercellular signaling molecules contribute to physiological diversities in humans, we curated 457 human G-protein-coupled receptors (GPCRs) and their cognate ligand genes as well as 382 human non-GPCR receptor and ligand genes (Supplemental Table 1; Ben-Shlomo et al. 2003; Semyonov et al. 2008). We started by using the population differentiation statistic $F_{\mathrm{ST}}$ to identify the leads for functional characterization (Lewontin and Krakauer 1973; Akey et al. 2002; Li et al. 2008).

We computed the $F_{\mathrm{ST}}$ for the coding SNPs of GPCR and ligand genes and compared the result with those for coding SNPs of all other human genes. $F_{\mathrm{ST}}$ was computed between all possible pairs of HapMap II populations (YRI [African, Yoruba from Ibadan], CEU [European, United States residents with northern and western European ancestry], and ASN [East Asian, pooled samples of Chinese from Beijing $\{\mathrm{CHB}\}$ and Japanese from Tokyo $\{\mathrm{JPT}\}])$. Distributions of $F_{\mathrm{ST}}$ for either the synonymous or nonsynonymous SNPs between any two HapMap II populations showed no difference (all $P>0.01$, Kolmogorov-Smirnov test) (Supplemental Fig. 1). Likewise, studies of the $F_{\mathrm{ST}}$ of coding SNPs in 382 non-GPCR receptor and ligand genes have shown similar cumulative distribution function (CDF) plots, suggesting that there is no difference in $F_{\mathrm{ST}}$ distribution between the GPCR and the non-GPCR groups $(P>0.01$, Kolmogorov-Smirnov test) (Supplemental Fig. 2$)$. These results suggest that, when analyzed as a whole set, the coding SNPs of human polypeptide receptor and ligand genes do not have a significantly elevated $F_{\mathrm{ST}}$.

Nevertheless, at the individual-gene level, dozens of coding SNPs in these receptor and ligand genes have a high $F_{\mathrm{ST}}(>0.5)$ between select pairs of populations (Supplemental Tables 2, 3). Among GPCRs and their cognate ligands, DRD5, DARC, CELSR1, CCL23, GIP, MC1R, EMR1, GRM1, CALCR, CXCR6, GPR39, and $D R D 3$ were found to have nonsynonymous SNPs with a high $F_{\mathrm{ST}}$, which suggests that these SNPs are likely to be targets of selection. On the other hand, nonsynonymous SNPs in EDAR, which has been repeatedly shown to be under positive selection (Bryk et al. 2008; Fujimoto et al. 2008), and several immune response-related genes (e.g., IL4R, TNFRSF10A, TRAF3, IL29, IL2ORA, IL1RL1, TNFRSF6B, and PTPRA) in the non-GPCR group were found to have high $F_{\mathrm{ST}}$ scores in select pair(s) of the populations.

Importantly, we found that the nonsynonymous SNP (rs2291725) in exon 4 of the glucose-dependent insulinotropic polypeptide gene (or gastric inhibitory peptide, GIP; referred to as the $G I P^{103 T / C}$ mutation in the following text) on chromosome 17 is highly linked with a cluster of neighboring SNPs within a $250-\mathrm{kb}$ region (starting from rs8079874 to rs2291726) and has an $F_{\text {ST }}$ value in the top $0.5 \%$ of all nonsynonymous SNPs in comparisons between the ASN and YRI populations (Fig. 1A; Supplemental Table 2). In contrast, $F_{\mathrm{ST}}$ estimates in comparisons between CEU and YRI or between CEU and ASN were not different from the

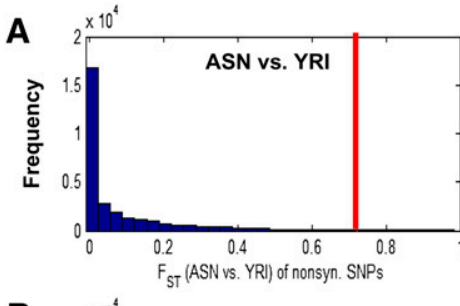

\section{B}
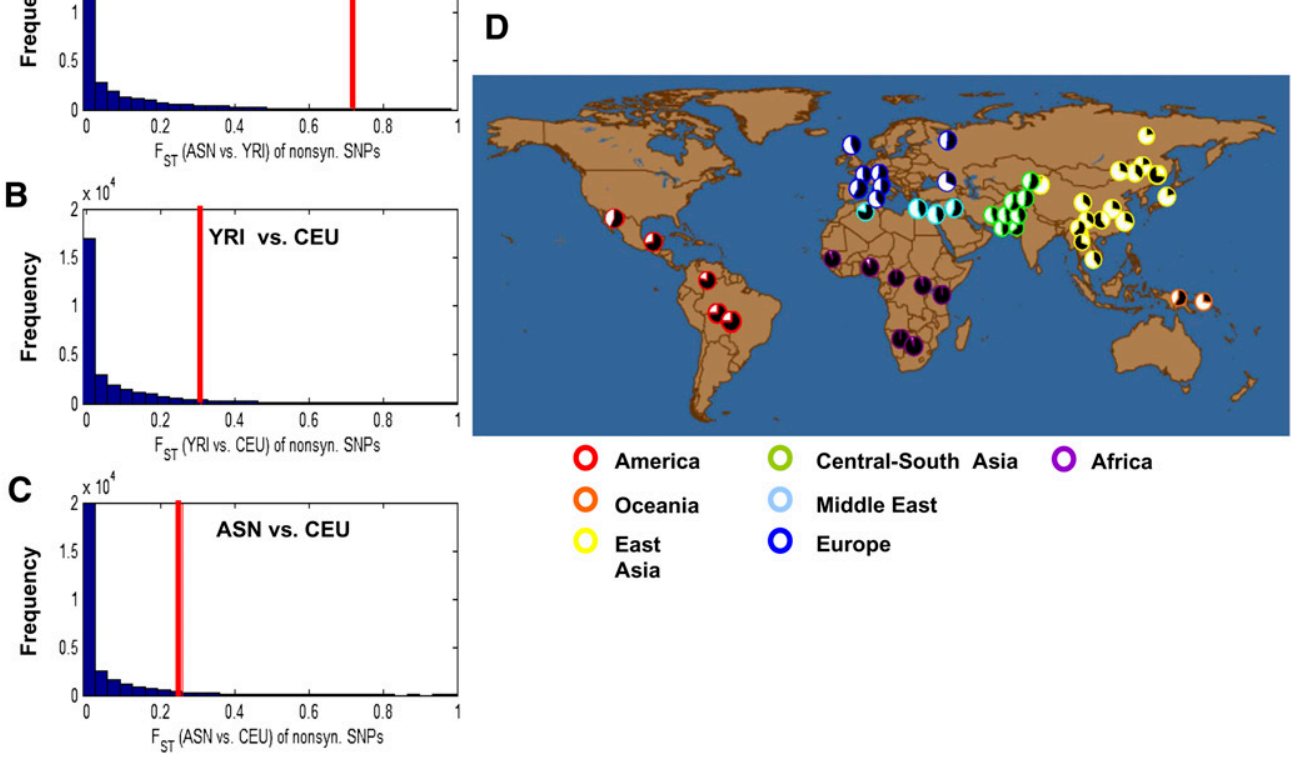

Figure 1. Differential distribution of alleles at rs 2291725 in human populations. $(A-C)$ The distribution of the $F_{S T}$ for nonsynonymous SNPs across the human genome and the $F_{S T}$ for rs2291725. $F_{\text {ST }}$ estimations between ASN and YRI (A), YRI and CEU (B), and ASN and CEU (C) are shown in the $x$-axis. The red vertical bar indicates the corresponding values of $F_{\mathrm{ST}}$ for rs2291725. The $y$-axis represents the frequency of SNPs with a given $F_{\mathrm{ST}}$ estimate. Statistical significance for comparisons in $A, B$, and $C$ is indicated with empirical $P=0.0039,0.058$, and 0.047 , respectively. The number of coding SNPs that were analyzed in the $A, B$, and $C$ histograms was $48,526,48,674$, and 48,075 , respectively. Among these SNPs, the number of nonsynonymous SNPs in the $A, B$, and $C$ histograms was 29,033, 29,026, and 28,774, respectively. (D) Distribution of rs2291725 in the HGDP-CEPH (944 unrelated samples) populations. Pie charts represent the proportion of each genotype by geographic region. The ancestral GIP ${ }^{103 T}$ allele (black pie) occurs at a higher frequency in African and American populations, whereas the majority of Eurasian populations have a higher frequency of the derived GIP ${ }^{103 C}$ allele (white pie).

\section{Genome Research} www.genome.org 
genome average (Fig. 1B,C). Consistently, data from the HGDPCEPH project (Center d'Etude du Polymorphisme Humain-Human Genome Diversity Panel; 944 unrelated individuals from 52 populations) (Cann et al. 2002; Rosenberg 2006; Li et al. 2008) and the Human Genome Center at the University of Tokyo (752 Japanese individuals, $G I P^{103 C} / G I P^{103 T}=0.732 / 0.268$ ) showed that the derived $G I P^{103 C}$ allele frequency at rs2291725 is much higher (>60\%) in the majority of East Asian populations and varies widely among other populations: ranging from $0.0 \%-9.5 \%$ in sub-Saharan Africans and increasing to $>40.0 \%$ in European and Middle Eastern populations (Fig. 1D; Table 1; Supplemental Table 5).

GIP encodes one of the two incretin hormones (glucagon-like peptide-1[GLP-1] and GIP) in humans and plays a critical role in normal carbohydrate and lipid metabolism (Kim and Egan 2008). After ingestion of nutrients, GIP secreted from duodenal and jejunal $\mathrm{K}$ cells acts on pancreatic $\beta$ cells to stimulate the release of insulin, which thereby ensures the prompt uptake of glucose and lipids into the tissues. Abnormal regulation of GIP signaling leads to altered carbohydrate metabolism and lipid accumulation at the enteroinsular and enteroadipocyte axis, respectively (Miyawaki et al. 2002; Fulurija et al. 2008; Isken et al. 2008; Kim and Egan 2008). In mice, the deletion of the GIP receptor (Gipr) led to impaired first-phase glucose-stimulated insulin release (Miyawaki et al. 2002), whereas exogenous GIP was found to worsen postprandial hyperglycemia in patients with type 2 diabetes (Chia et al. 2009). In addition to effects on glucose homeostasis, GIP has been shown to promote obesity in mice that were fed a high-fat diet (McClean et al. 2007; Gniuli et al. 2010). Because the incretin effect induced by the oral glucose intake leads to a higher insulin response compared with that from a matched intravenous glucose stimulation, the regulation of glucose levels by GIP represents a critical endocrine circuit to monitor exogenous energy intake and regulate subsequent storage (Kim and Egan 2008). In addition, the critical role of GIP signaling in energy-balance regulation has been highlighted by recent studies that showed that variants at the GIPR locus are associated with glucose levels $2 \mathrm{~h}$ after an oral glucose challenge test used in the diagnosis of type 2 diabetes (Ingelsson et al. 2010; Saxena et al. 2010). On the other hand, epidemiological studies have shown that the prevalence of different forms of diabetes and obesity as well as the regulation of glucose metabolism vary widely among ethnic groups (Buchanan and Xiang 2005; Kim and Egan 2008). Thus, the observed high population differentiation in GIP polymorphisms could be associated with the adaptations of incretin physiology to recent changes in diets and cultures in select human populations. To test this hypothesis, we fine mapped the GIP locus and tested the functions of GIP variants in vitro and in vivo.

\section{Variants at the GIP locus were partially selected in Eurasian populations}

Analyses of linkage disequilibrium (LD) in the GIP region for the three HapMap II populations showed that extended LD blocks are present in the CEU and ASN chromosomes, and these blocks encompass GIP and the neighboring UBE2Z, SNF8, and ATP5G1 genes (Supplemental Fig. 3A,B, red square, $D^{\prime}=1$, likelihood of odds [LOD] scores $>2$ ). In contrast, the majority of SNP pairs in the GIP region of the YRI chromosomes exhibited a low LOD and a low $r^{2}$ (Supplemental Fig. 3C, blue square, $\mathrm{D}^{\prime}=1$, LOD scores $<2$ ). Consistent with the LD analysis, plots depicting the haplotype map showed that most of the chromosomes with the derived $G I P^{103 C}$ allele in the ASN population have haplotypes extending $>200 \mathrm{~kb}$ and are significantly longer compared with chromosomes with the ancestral $G I P^{103 T}$ allele (Fig. $2 \mathrm{~A}$, middle panel, $P<0.001$ ). In contrast, most chromosomes in YRI did not exhibit an extended haplotype surrounding the GIP ${ }^{103}$ allele (Fig. 2A, bottom panel). These results were reflected in the plots of extended haplotype homozygosity (EHH) decay curves (Fig. 2B). In ASN and CEU, the EHH curve for chromosomes carrying the derived GIP $^{103 C}$ allele extends much further than that for the ancestral allele. To test whether the area under the EHH curve is greater for a selected allele than for a neutral allele, we calculated the integrated haplotype score (iHS) for rs2291725 as a core marker (Voight et al. 2006). By using a coalescent model that generated 10,000 data sets from the same length of genome region $(750 \mathrm{~kb})$ with the same sample size (180 chromosomes), we found that the observed iHS for the derived allele in ASN (iHS $=-0.753)$-but not CEU ( $\mathrm{iHS}=-0.131)$ deviated significantly from the neutral distribution $\left(P<1 \times 10^{-4}\right)$ (Supplemental Fig. 4A). We also performed coalescent simulations that took into account the effects of demography (e.g., population bottleneck) (Supplemental Fig. 4B) and recombination hotspot, respectively (Hellenthal and Stephens 2007; Gutenkunst et al. 2009; Supplemental Methods). Consistently, we found that no iHS for the simulated haplotype sets is more negative than the observed iHS for rs2291725 under the bottleneck scenario (empirical $P<1 \times 10^{-4}$ ), and only a few are in the presence of a recombination hotspot (empirical $P<8 \times 10^{-4}$ ) (Supplemental Fig. 4A). These results indicated that the observed iHS has deviated significantly from the neutral distribution even after adjusting for the bias that may have been introduced by a bottleneck in demography or heterogeneous recombination events. Thus, it is unlikely that neutral evolution alone explains the observed long haplotypes that carry the derived GIP ${ }^{103 C}$ allele in the ASN population.

Further examination of the extended haplotype blocks in ASN showed that rs2291725 is highly linked with another 43 SNPs

Table 1. Human GIP SNP rs2291725 exhibits a high population differentiation characteristic in the International HapMap II Project data set

\begin{tabular}{|c|c|c|c|c|c|c|c|c|c|}
\hline \multirow[b]{2}{*}{ Population } & \multirow[b]{2}{*}{ Chromosome no. } & \multicolumn{2}{|c|}{ rs2291725 allele frequency } & \multicolumn{3}{|c|}{ rs2291725 genotypes } & \multicolumn{3}{|c|}{$F_{\mathrm{ST}}$ vs. } \\
\hline & & $G I P^{103 T}$ & $G I P^{103 C}$ & $T / T$ & $\mathrm{~T} / \mathrm{C}$ & $\mathrm{C} / \mathrm{C}$ & YRI & CEU & ASN \\
\hline YRI & 120 & 0.950 & 0.050 & 0.900 & 0.100 & 0.000 & - & 0.24 & $0.48^{\mathrm{a}}$ \\
\hline CEU & 120 & 0.517 & 0.483 & 0.267 & 0.500 & 0.233 & 0.24 & - & 0.08 \\
\hline ASN & 178 & 0.245 & 0.755 & 0.090 & 0.314 & 0.595 & $0.48^{\mathrm{a}}$ & 0.08 & - \\
\hline All & 418 & 0.524 & 0.476 & & & & & & \\
\hline
\end{tabular}

Genotypes were analyzed as described using the SPSmart v3 and Haplotter (Voight et al. 2006; Amigo et al. 2008). The average frequency of two alleles-derived allele GIP $P^{103 C}$ and ancestral chimpanzee allele GIP ${ }^{103 T}$-at rs 2291725 is approximately even in the overall HapMap population: Only 5.0\% of YRI chromosomes contain GIP $103 C$ compared with $48.3 \%$ and $75.5 \%$ of CEU and ASN chromosomes that carry the derived allele, respectively.

${ }^{\mathrm{a}} P<0.05$. 


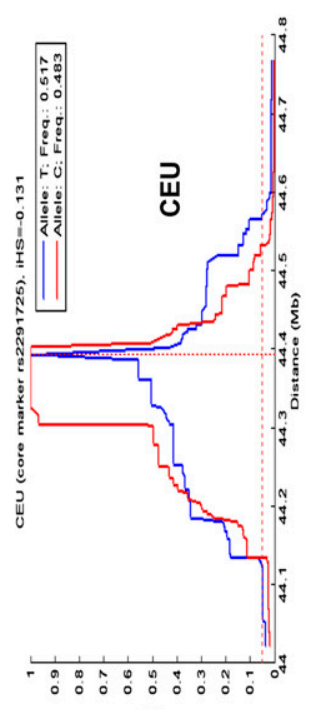

$\mathrm{HH}$

m

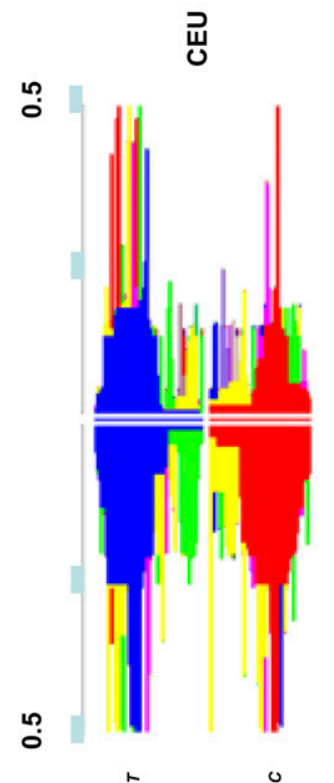

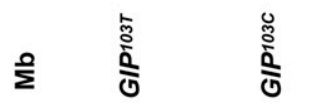
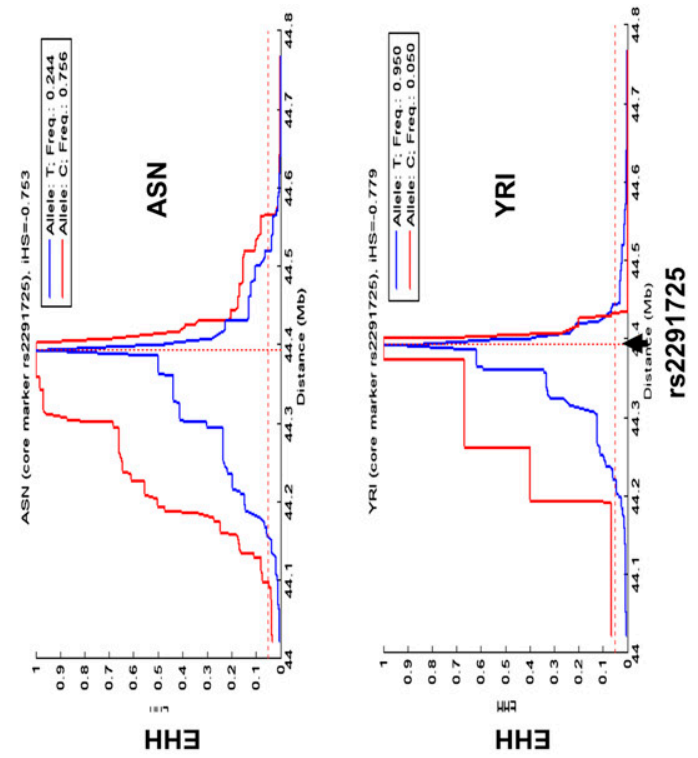

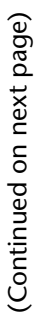

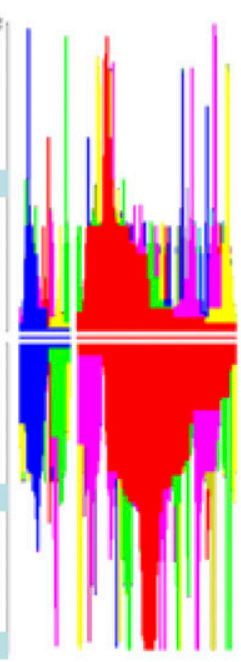

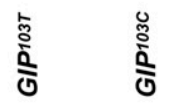

능 


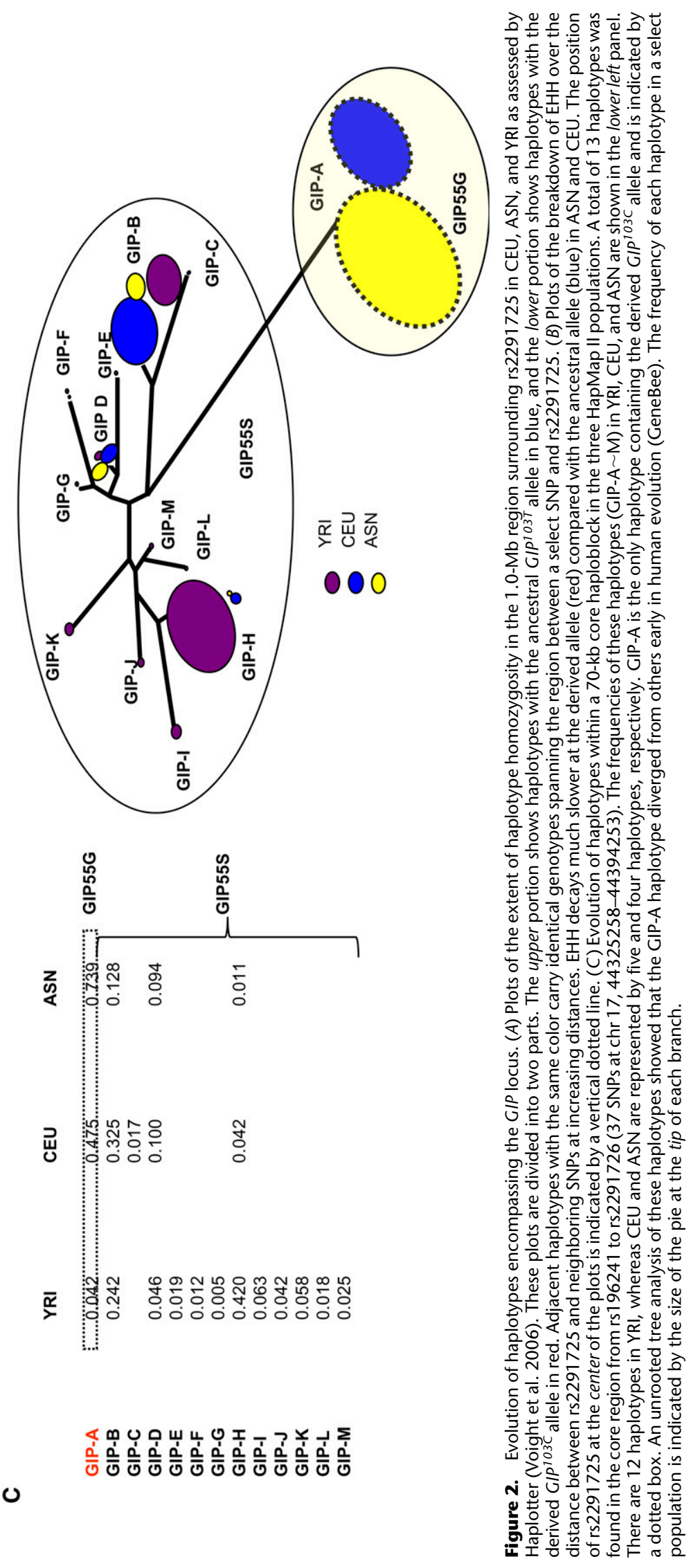


within the adjacent $250-\mathrm{kb}$ region, and in a 70-kb core region (rs1962412 to rs2291726; Genome build 36.3, chr 17, 44325258-44394253), the derived GIP ${ }^{103 C}$ allele is associated with a single haplotype (Fig. 2C, haplotype GIP-A; Supplemental Fig. 3D; Supplemental Table 4). In contrast, the ancestral GIP $P^{103 T}$ allele found in the majority of the YRI chromosomes is represented by 12 different haplotypes (Fig. 2C, haplotypes GIP-A, GIP-B, and GIP-D-M; Supplemental Fig. 3D). An unrooted tree analysis of these haplotypes confirmed that the evolutionary trajectory of the $G I P^{103 C}$-associated haplotype is distinct from other haplotypes (Fig. 2C). Given the presence of several characteristic patterns, including highly differentiated alleles, high frequency-derived alleles, and relatively long derived haplotypes, these data suggested that pre-existing polymorphisms at the GIP locus were partially selected in ASN and possibly in CEU at times post-dating the separation of the YRI and Eurasian populations (Smith and Haigh 1974).

GIP encodes a GIP peptide containing the variable residue (Ser103 or Gly103) at rs2291725

Whereas the selection at the GIP locus could be attributed to a single variant or a combination of SNPs, the nonsynonymous rs2291725 provided a tangible target for functional analyses of the causal mutation. To explore whether rs2291725 represented a causal variant and provided a benefit to its carriers, we investigated the function of the GIP peptides containing the variable residue (Ser103 for GIP ${ }^{103 T}$ or Gly103 for $G I P^{103 C}$ ). GIP was originally characterized as a 42 -amino-acid peptide derived from proteolytic processing at the monobasic cleavage sites at residues 51 and 94 of the GIP open reading frame (Moody et al. 1984; Takeda et al. 1987; Kim and Egan 2008). Although residue 103 is located outside the conventional mature GIP sequence (residues 52-93) (Fig. 3A, upper panel), we noticed that a conserved dibasic cleavage site (Arg-Lys, residues 106$107)$ is located 13 amino acids downstream from the conventional cleavage site in primates, dogs, cats, cows, pigs, and horses (Fig. 3A, upper panel). Thus, post-translational cleavage at this alternative processing site could generate an extended GIP isoform 13 amino acids longer (Fig. 3A, lower panel; the ancestral GIP55S and the derived GIP55G). To
A
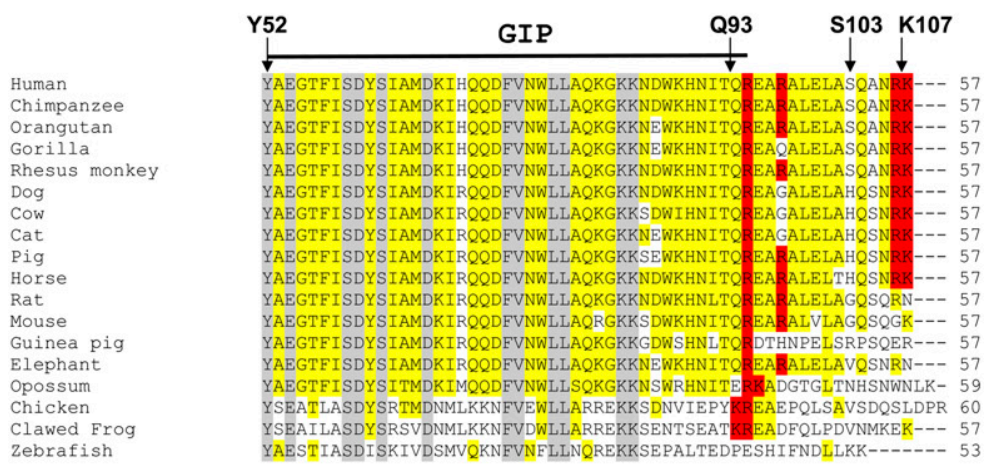

GIP55G and GIP55S

YAEGTFISDYSIAMDKIHQQDFVNWLLAQKGKKNDWKHNITQREARALELASQAN

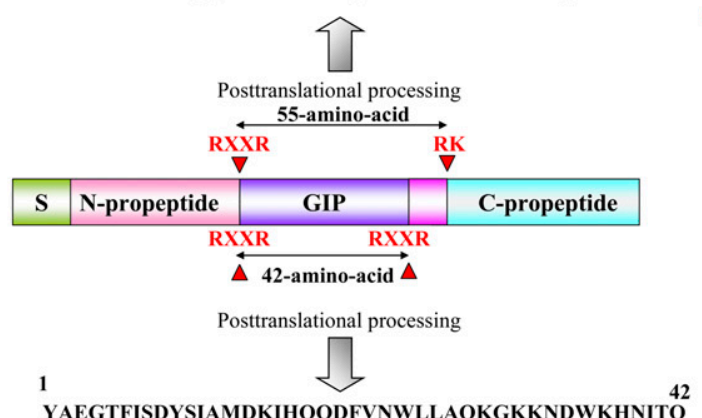

GIP

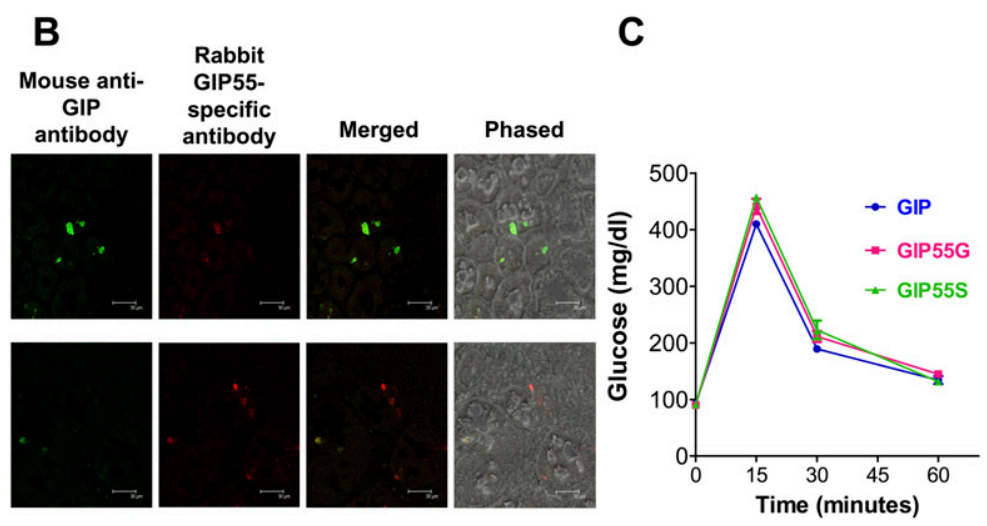

Figure 3. An extended GIP peptide is expressed in human gut cells. $(A)$ Alignment of human GIP (residues Y52 to K107) with corresponding residues from 17 other vertebrates showed that the GIP open reading frame contains alternative basic cleavage sites for the generation of multiple GIP isoforms in primates, dogs, cats, cows, pigs, and horses (upper panel). The mature peptide region is indicated by a dark horizontal bar above the alignment. Residues that are conserved from teleosts to humans are indicated by a gray background. Putative basic cleavage sites are indicated by a red background. The position of the variable residue 103 is indicated by an arrow. Alternative post-translational processing of proGIP could lead to the generation of a 42-amino-acid mature GIP and an extended 55-amino-acid isoform (GIP55G or GIP55S) that differ at position 52 (lower panel). (B) GIP and GIP55 peptides are colocalized in the duodenum cells. Immunoreactive GIP and GIP55 were detected in select duodenum cells by immunofluorescent staining. The right panels showed the dark field and phased contrast images of merged immunofluorescent signals $(800 \times)$. The white horizontal bar in each panel represents a distance of $30 \mu \mathrm{m}$. (C) GIP, GIP55G, and GIP55S suppressed exogenous glucose in fasting rats in vivo. Each of the three GIP peptides reduced glucose contents in the blood to basal levels at $1 \mathrm{~h}$ after injection of the peptide and glucose. Each data point represents the mean \pm SEM of triplicate samples. Similar results were observed in five separate experiments. 
investigate this possibility, we analyzed whether the GIP55 peptide is expressed in gut cells of the proximal small intestine. In support of our hypothesis, the immunohistochemical analysis of human duodenum sections with a rabbit GIP55-specific antibody and a mouse anti-GIP antibody showed that immunoreactive GIP55 and GIP are colocalized in select duodenum cells, suggesting that GIP55 is present in gut cells that normally express GIP (Fig. 3B). To study whether GIP55 is secreted into general circulation, we then analyzed the presence of GIP55 in serums of individuals $30 \mathrm{~min}$ after a regular breakfast meal using a sandwich ELISA assay that detects the extended C-terminal sequences specific to GIP55. Consistently, we found that GIP55 is present in human serum and constitutes $\sim 1 \%-3 \%$ of the total GIP after a meal (GIP55, $2.91 \pm$ $0.41 \mathrm{pmol} / \mathrm{L}$; total GIP, $95.1 \pm 9.41 \mathrm{pmol} / \mathrm{L}, N=6)$. Thus, depending on the genotype, humans could contain two $\left(G I P^{103 T / T}\right.$ : GIP+GIP55S; GIP ${ }^{103 C / C}:$ GIP+GIP55G) or three GIP isoforms $\left(\right.$ GIP103 ${ }^{T / C}$ : GIP+GIP55S+GIP55G) (Fig. 3A).

Because the receptor-activation domain of GIP is located at the $\mathrm{N}$ terminus of the peptide, we reasoned that alternative processing at the $\mathrm{C}$ terminus of GIP55 peptides is unlikely to decimate their bioactivity. Indeed, functional testing of the synthetic GIP isoforms (GIP, GIP55G, and GIP55S) in vivo showed that similar to conventional GIP, the extended GIP55G and GIP55S suppress hyperglycemia to similar extents in a time-dependent manner in fasting rats (Fig. 3C).

The ancestral GIP55S and the derived GIP55G peptides exhibit distinct bioactivity profiles in vitro

To compare the bioactivity of GIP isoforms and variants, we measured their receptor-activation activities in vitro using HEK293T cells expressing a recombinant human GIP receptor. As expected, treatments of GIP led to dose-dependent increases of cAMP production in transfected cells (Fig. 4A, top left panel). Unlike conventional GIP, which exhibits an $\mathrm{EC}_{50}$ of $\sim 0.9 \pm 0.21 \mathrm{nM}$, the extended GIP isoforms have approximately threefold lower potencies (GIP55G, $3.2 \pm 0.21 \mathrm{nM}$; GIP55S, $2.6 \pm 0.23 \mathrm{nM}$ ) (Supplemental Table 6). Importantly, we found that the derived GIP55G consistently increases cAMP production to significantly higher levels compared with the ancestral GIP55S (Fig. 4A, top left panel). Because GIP is known to be susceptible to serum degradation in vivo, we also studied the stability of GIP isoforms in human serum in vitro. Surprisingly, we found that GIP55G and GIP55S are more resistant to degradation by either pooled normal human serum (Fig. $4 \mathrm{~A}$ ) or pooled complement-preserved human serum (Supplemental Fig. 5). The ranking of potency on receptor activation shifted from GIP $>$ GIP55G > GIP55S at $0 \mathrm{~h}$ to GIP $=$ GIP55G $=$ GIP55S and GIP55G > GIP55S $\geq$ GIP, respectively, after a 6 -h or a 12 -h preincubation with either normal serum (Fig. 4A), or complementpreserved serum (Supplemental Fig. 5). Plots of $\mathrm{EC}_{50}$ data in relation to the length of incubation showed that the slope of changes in the bioactivity for GIP is significantly steeper than that of GIP55G (Fig. $4 \mathrm{~B}, P=0.0023)$. On the other hand, coincubation with a recombinant dipeptidyl peptidase IV (DPP IV) led to similar extents of degradation of these peptides (Supplemental Table 7). Thus, the resistance to serum degradation by GIP55G cannot be attributed to a resistance of DPP IV, which represents the major processing enzyme that degrades GIP and GLP-1 in vivo by cleaving these peptides at position 2 of the $\mathrm{N}$ terminus (Kim and Egan 2008). These data suggested that the rise in the frequency of GIP $^{103 C}$ in Eurasian populations could be associated with the quantitative increase in the overall potency of GIP55G. Although the nature of the selective
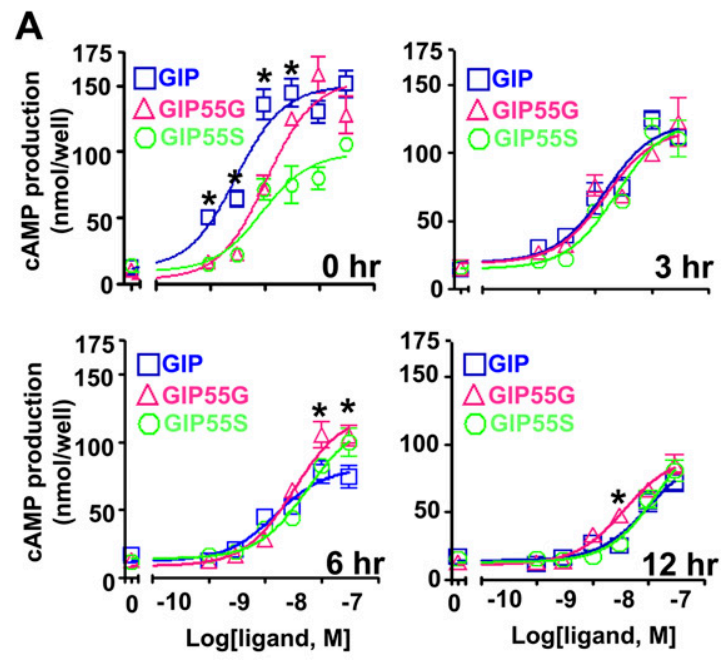

B

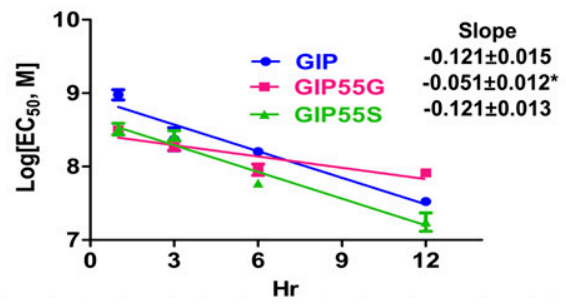

Figure 4. The variation at rs 2291725 affects the bioactivity of translated products. (A) GIP55G peptide is resistant to serum degradation. Treatments of GIP receptor-expressing HEK293T cells with GIP, GIP55G or GIP55S led to dose-dependent increases of cAMP production (top left panel). Receptor-activation activities of peptides were also analyzed following incubation with pooled normal human serum for 3, 6, or $12 \mathrm{~h}$. Cells were treated with synthetic peptides for $12 \mathrm{~h}$; the signaling is reported as total CAMP contents in cell lysates. Error bars, SEM of triplicate samples. Significant differences in CAMP production between GIP and GIP55G treatments at a given peptide concentration are indicated by asterisks $(P<0.01)$. In the control group, cells were treated with an aliquot of human serum without a synthetic peptide. Similar results were observed in three separate experiments. (B) Comparison of the slopes of $\mathrm{EC}_{50}$ trend lines for GIP, GIP55G, and GIP55S after treatments with pooled human serum for the indicated time-spans. The slope of the GIP55G group is significantly different from that of the GIP group ( $\left.{ }^{*} P=0.0023\right)$.

advantage conferred by the GIP55 peptides is not clear, we speculate that GIP ${ }^{103 C}$ could represent a risk allele in ancestors of YRI populations but provide a selective advantage in Eurasians.

\section{The derived GIPIO3C allele arose to dominance in East Asians $\sim 8100$ yr ago}

Because energy-balance regulation-related loci are subject to selection pressures that fluctuate over time in response to environmental and culture changes, genetic responses to changes in the human diet are more likely associated with incomplete signatures of selection or even signatures of balancing selection (Charlesworth 2006; Pritchard et al. 2010). Based on this understanding, we speculated that the GIP $P^{103 C}$ and $G I P^{103 T}$ alleles likely confer distinct advantages depending on the history of culture changes (Allison 1956; Turner et al. 1979) and that the selection of $G I P^{103 C}$ could occur at a time when humans experienced major shifts in subsistence culture. To investigate this possibility, we estimated the age of the GIP ${ }^{103 C}$-associated haplotype. Under the neutrality, the average age of a polymorphism with the frequency 
$p$ is estimated to be $-4 N_{e}[p(\log p) /(1-p)]$ (Kimura and Ota 1973; Slatkin and Rannala 2000). With the assumption of $N_{e}=5000$ for each population, this yielded $77,500,350,000$, and $425,000 \mathrm{yr}$ for the derived allele to arise to its current frequencies in the YRI, CEU, and ASN populations, respectively. These estimates are obviously incompatible with the archaeological evidence showing that modern humans originated $\sim 195 \mathrm{kyr}$ ago in Sub-Saharan Africa and that a first wave of migration to the Arabic peninsula occurred $\sim 60$ to $55 \mathrm{kyr}$ ago, which was followed by migration toward Northern Eurasia 40 kya (McDougall et al. 2005; Klein 2009). Consequently, we estimated the age of the $G I P^{103 C}$-associated haplotype on the basis of the decay of haplotypes (Reich 1998; Stephens et al. 1998). Based on a recombination rate derived from estimates of LD of the HapMap data set (McVean et al. 2004), the analysis showed that ASN contains a dominant ancestral haplotype and that the $G I P^{103 C}$-associated haplotypes arose to dominance $\sim 8100 \mathrm{yr}$ ago in East Asians. Because this dating approach relies on the linkage map derived from estimates of LD, and because discrepancies between LD maps and the pedigreebased recombination maps are significant in many genomic regions (Clark et al. 2010), we also performed the analysis using alternative estimates of recombination rate, which range from 0.5 $3.03 \mathrm{cM} / \mathrm{Mb}$ in three studies of pedigree-based recombination maps (i.e., deCODE, Marshfield, and Genethon) (Dib et al. 1996; Broman et al. 1998; Kong et al. 2002). Using these recombination rates, we obtained alternative estimates of the age to be between 11,800 and 2000 yr. On the other hand, dating is unattainable for CEU because the ancestral GIP $^{103 C}$ haplotype in this population cannot be identified unambiguously, perhaps because that mutation in the region is effectively "saturated" (Supplemental Fig. 6). Given that GIP signaling plays a critical role in the regulation of glucose and lipid metabolism, it is plausible that the increased prevalence of the $G I P^{103 C}$ allele in Eurasians is a consequence of changes in foraging skills or in population dynamics associated with the emergence of agricultural societies in the Eurasian continent 12,000 to 7000 yr ago (Balter 2007; Fuller et al. 2009; Jones and Liu 2009; Richards and Trinkaus 2009; Gibbons 2010).

\section{Discussion}

Based on the gene age estimation and biochemical analyses, our study revealed a functional mutation that is associated with the selection of the GIP locus in East Asian populations $\sim 8100 \mathrm{yr}$ ago and the presence of a cryptic GIP isoform. Specifically, we showed that the inventory of human GIP peptides has recently diverged and that individuals could express three different combinations of GIP isoforms (GIP, GIP55S, and GIP55G) with distinct bioactivity profiles. Future study of how this phenotypic variation affects glucose and lipid homeostasis in response to different diets and of which physiological variations in humans can be attributed to prior gene-environmental interactions at the GIP locus is crucial to a better understanding of human adaptations in energy-balance regulation.

Taking advantage of the availability of genome information from diverse human populations, recent studies have revealed a number of loci and variants that describe phenotypic variation in appearance, physiological parameters, and pathological responses to diseases (Sabeti et al. 2005; Voight et al. 2006, 2010; Sulem et al. 2007; Tishkoff et al. 2007; Genovese et al. 2010; Gibbons 2010; Leslie 2010; Ng et al. 2010; Simonson et al. 2010). In addition, it has been shown that human genomes contain hundreds of loci that exhibit varying degrees of positive selection (Kelley et al. 2006;
Voight et al. 2006; Sabeti et al. 2007; Barreiro et al. 2008; Akey 2009; Cai et al. 2009; Pickrell et al. 2009). These recent in silico findings on gene selection, perhaps due to differential gene-environmental interactions among populations, have opened the doors to human history and a better understanding of the prevalence of adaptations among human populations. However, few causal variants have been confirmed or linked to a phenotype (Akey 2009; Gibbons 2010; Nei et al. 2010). Thus, our finding that the high-frequency GIP $^{103 C_{-}}$ associated haplotypes in Eurasian populations are functionally relevant has provided a rare opportunity to better understand the environmental impact on human physiology at the enteroinsular and enteroadipocyte axes. It is generally accepted that a food source represents a potent force that influences selection and adaptive radiation in nature (Darwin 1859; Freeman and Herron 2003). For example, the external differences in beak morphology and speciation of Darwin's finches are believed to be results of adaptations that exploit particular types of seeds, insects, and cactus flowers on the Galápagos Islands (Schluter 2000). Likewise, changes in food source represented one of the most important selection pressures during transitions of human culture and posed a wide spectrum of challenges to the digestive and endocrine systems of our ancestors (Piperno et al. 2004; Balter 2007; Fuller et al. 2009; Jones and Liu 2009; Richards and Trinkaus 2009; Gibbons 2010). For instance, the ability to digest lactose in milk (lactase persistence) and the adoption of a pastoral culture has been linked to the selection of a variety of variants at the lactase locus in multiple ethnic groups at various time points during the last 10 millenniums (Tishkoff et al. 2007; Itan et al. 2009). Similarly, individuals from populations with high-starch diets tend to have more copies of amylases than do those from populations with lowstarch diets (Perry et al. 2007). It has long been hypothesized that our ancestors ate a low-carbohydrate, high-protein diet and that the adaptive response was manifested as insulin resistance, perhaps for coping with low dietary glucose (Miller and Colagiuri 1994). Because normal GIP signaling is crucial to normal glucose and lipid metabolism, we speculate that the selection of the GIP ${ }^{103 C}$ haplotypes could be pertinent to shifts in long-term energy-balance regulation after the emergence of agriculture, which provided a stable supply of high-starch staples and a reduced need for metabolic efficiency as opposed to the traditional huntergatherer societies (Miller and Colagiuri 1994; Wang et al. 2006; Balter 2007; Fuller et al. 2009; Jones and Liu 2009; Richards and Trinkaus 2009; Gibbons 2010; Luca et al. 2010; Richerson et al. 2010).

It was hypothesized by Neel almost $50 \mathrm{yr}$ ago that mismatches between prior physiological adaptations and contemporary environments can lead to health risks because the ancestral variants that have been selected for the organism's fitness or reproductive success may not be optimal for the individual's health in the new environment (Neel 1962). In support of this thrifty genotype hypothesis, a number of genes in humans and house mice have been implied to have coevolved with the emergence of agricultural societies (Prentice et al. 2005; Vander Molen et al. 2005; Shiao et al. 2008), and a rapid shift in diets is associated with the detrimental effects on human survival in a number of human populations (Anonymous 1989). Conceptually, the serum-resistant GIP55G carried by the GIP ${ }^{103 C}$ haplotype may have been beneficial for individuals who have unconstrained access to the food supply in many agricultural societies by preventing severe hyperglycemia. As selection pressure changed in these societies, the ancient $G I P^{103 T}$ haplotype could have become a liability and conferred a loss of fitness in the new environment. In addition, we speculate that the selection of GIP in East Asians may contribute to the heterogeneity 
in the risk of diabetes among major ethnic groups at the present time (Retnakaran et al. 2006; Nystrom et al. 2008; Ma and Chan 2009). Importantly, regardless of what the selection pressure might have been, our study indicated that the GIP locus was susceptible to recent changes in human environment and that the physiological variation stemming from this selection could bear important implications for understanding the phenotypic variation of metabolic syndromes such as diabetes and obesity. Nonetheless, it is important to note that the selection of the derived $G I P^{103 C}$ haplotypes could be a consequence of the coordinated actions of multiple SNPs at the GIP locus. Future analysis of the functionality of rs2291725 and linked SNPs is needed to elucidate the exact nature of the selection of $G I P^{103 C}$ haplotypes in the last 10 millenniums.

Taken together, our study has highlighted an unexpected complexity in the regulation of sugar and lipid metabolism among human populations; it has also illuminated the importance of understanding adaptations in genes associated with energy-balance regulation in the face of ongoing changes in our diets toward refined and high-energy convenience food as well as the emerging pandemics of diabetes and obesity in modern society.

\section{Methods}

\section{Genotype analysis}

\section{$\mathrm{F}_{S T}$ estimation and $L D$ plot}

The selected loci that have rapidly increased in frequency due to local positive selection are likely to show high levels of genetic differentiation, which can be quantified with the $F_{\mathrm{ST}}$ statistic (Lewontin and Krakauer 1973; Weir 1996). The principle of a number of estimators of $F_{\mathrm{ST}}$ is $F_{\mathrm{ST}}=\left(H_{\mathrm{T}}-H_{\mathrm{S}}\right) / H_{\mathrm{T}}$, where $H_{\mathrm{T}}$ is the heterozygosity of the total population and $H_{\mathrm{S}}$ is the average heterozygosity across subpopulations. The empirical distribution of $F_{\mathrm{ST}}$ or the average of $F_{\mathrm{ST}}$ over multilocus windows for the genomewide polymorphism data has been used to detect the genomic regions under positive selection (Akey et al. 2002). We computed the $F_{\text {ST }}$ for all nonsynonymous SNPs in the HapMap Project phases I and II, and the function snp_fst.m in PGEToolbox (Cai 2008) was used to calculate and present an unbiased estimate of $F_{\mathrm{ST}}$.

LD plots for SNPs within the CALCOCO2, ATP5G1, UBE2Z, SNF8, GIP, and IGF2BP1 gene regions from rs1422645 to rs8069452, spanning $200 \mathrm{~kb}$, were generated using HaploView 4.1 (Barrett et al. 2005). The LD blocks were determined using an $r^{2}$ threshold of 0.8 .

\section{Analysis of EHH and $i H S$}

The EHH plots were generated as described (Voight et al. 2006). We also computed the EHH statistic for the core SNP (rs2291725) as previously described (Sabeti et al. 2002). The EHH curve measures the decay of identity of haplotypes that carry the core SNP as a function of distance. When an allele rises rapidly in frequency due to strong selection, it tends to exhibit high levels of haplotype homozygosity, extending further than expected under a neutral model. For the analysis of EHH decay, haplotypes in the genomic region that encompasses a 750-kb region centered on the GIP gene and contains 388 phased SNPs were downloaded from the HapMap project website.

The iHS statistic detects whether the area under the $\mathrm{EHH}$ curve is greater for a selected allele than for a neutral allele (Voight et al. 2006). Large negative values indicate unusually long haplotypes carrying the derived allele. To test whether the observed iHS for rs2291725 is significantly deviated from the expected values derived from neutral evolution, we used a coalescent model and generated 10,000 replicated haplotype sets using the coalescent simulator $m s$ (Hudson 2002). We adopted parameters that are compatible with the sample size (180 chromosomes) of the ASN population and the length of genomic region $(750 \mathrm{~kb})$ that was analyzed. The simulation was conditioned based on recombination rate $=9.7 \times 10^{-7} \mathrm{cM} / \mathrm{bp}, N_{0}=10,000$, and number of segregating sites $=388$. We also required that each replicate contain at least one segregating site in which the derived allele frequency reaches $\sim 0.75$ and that the site is located in the center of the haplotype (that is, between a $370-$ and $380-\mathrm{kb}$ area of the $750-\mathrm{kb}$ region in total). With these conditions, we found no iHS value for a simulated data set to be more negative than the observed iHS (empirical $P<1 \times 10^{-4}$ ) (Supplemental Fig. 4A).

\section{Estimation of the age of $\mathrm{GIP}^{103 \mathrm{C}}$ haplotype}

Under positive selection, a derived, or novel, allele can quickly rise to a high frequency. As the allele ages, recombination causes the breakdown of the LD within the existing linked alleles, and mutation leads to the accumulation of new linked variations. The allele's age can be estimated by the decay of the haplotype carrying the allele (Stephens et al. 1998). The length of the haplotype retained between different copies of the allele shortens over time due to recombination and mutation, which is modeled using a Poisson process by Reich and Goldstein (1999). The probability that a haplotype remains ancestral (i.e., that the haplotype that carries the derived allele retains the status of high frequency right after being selected) is $P=\mathrm{e}^{-G(r+u)}$, where $G$ is generations, $r$ is the recombination rate, and $u$ is the mutation rate. For a given allele in the derived haplotype, the haplotype-decay approach estimates the number of generations $G$ in terms of $P$ (the probability that a given haplotype does not change from its ancestor) (Stephens et al. 1998; Reich and Goldstein 1999).

In ASN, the GIP LD block is $91 \mathrm{~kb}$ long and contains eight distinct haplotypes (1-8 from top to bottom in Supplemental Fig. 6). Haplotypes 1-4 are GIP ${ }^{103 C}$ associated and are derived. Among these derived haplotypes, haplotype 1 is apparently the ancestral haplotype from which haplotypes 2-4 were derived. The frequency of haplotype 1 in $G I P^{103 C}$-associated haplotypes is $P^{\prime}=$ 0.803 . We obtained the recombination rate derived from estimates of LD (McVean et al. 2004) from the website of the HapMap project (http://hapmap.ncbi.nlm.nih.gov/). Regression analysis with data points of different physical lengths versus genetic map lengths gave the regression function: $y=0.93 x-0.018$, where $x$ is the physical distance $(\mathrm{Mb})$ and $y$ is the genetic distance $(\mathrm{cM})$. The genetic distance of the $91-\mathrm{kb}$ region was estimated to be $0.0666 \mathrm{cM}$ (i.e., $0.0666 \%$ chance of crossing over in a single generation), which gives a rate of recombination $r=6.66 \times 10^{-4}$ per generation. We took the mutation rate of the region $u=1.0 \times 10^{-5}$, based on an estimation of the haploid mutation rate of $\sim 1.1 \times 10^{-8}$ per base per generation (Roach et al. 2010). We assumed that the most common haplotype is the ancestral haplotype and used $P^{\prime}$ obtained above as an approximation of $P$. Using $G=-\ln \left(P^{\prime}\right) /(r+u)$, we obtained $G=325$ (or $8100 \mathrm{yr}$ ).

\section{Phenotype tests}

\section{Reagents}

Synthetic GIP peptides were obtained from Genescript and the American Peptide Company. The extended GIP55G and GIP55S isoforms were synthesized by the Stanford University PAN facility and GL Biochem. Pooled normal human serum, pooled complement-preserved human serum, and serum from individuals were obtained from Innovative Research and ProteoGenex. Stocks of different hormones were prepared in phosphate-buffered saline 
and diluted in a serum-free culture medium. In addition to routine chemistry and mass-spectrometry assessments, we verified the quantity of different GIP isoforms using a human GIP enzymelinked immunosorbent assay (ELISA; Linco Research).

\section{Immunohistochemical analyses and ELISA}

Total GIP levels in human serums were measured using a sandwich human GIP ELISA kit (Linco Research), and assays were performed with a programmable ELISA plate washer. The minimum detection limit of the assay was $8.1 \mathrm{pg} / \mathrm{mL}$. For the measurement of GIP55, human serums were partially purified with C18 chromatography, and the secondary antibody of the human GIP ELISA kit was substituted with a rabbit polyclonal antibody specific for the last 13 amino acids of GIP55 (REARALELASQAN). The GIP55-specific antibodies were generated using a KLH-conjugated CREARALELASQAN peptide (Covance Research Products and Genescript).

For immunohistochemical analyses, human duodenum sections (BioChain Institute) were dewaxed with xylene and maintained for $10 \mathrm{~min}$ at $95^{\circ} \mathrm{C}-99^{\circ} \mathrm{C}$ in $10 \mathrm{mM}$ sodium citrate buffer (pH 6.0), followed by cooling on the bench top. Sections were immunostained with a mouse monoclonal anti-GIP antibody (Abbiotec) and a rabbit GIP55-specific antibody overnight at $4^{\circ} \mathrm{C}$, followed by incubation with fluorochrome-conjugated secondary antibodies (Invitrogen) for $1 \mathrm{~h}$ at room temperature in the dark. Signals for GIP and GIP55 were detected using an Alexa 488 donkey anti-mouse antibody (488 nm, 1:2500 dilution) and a Texas Red-conjugated goat anti-rabbit antibody (594 nm, 1:500 dilution), respectively, with a Leica SP2 single- and multi-photon confocal microscope.

\section{The in vivo glucose suppression assay}

Eight-week-old Sprague-Dawley rats (Charles River Laboratories, Inc., Wilmington, MA) were fasted overnight for $20 \mathrm{~h}$. To measure the GIP isoforms' ability to reduce blood glucose levels in vivo, fasting rats were injected with a select GIP peptide $(100 \mathrm{nmol} / \mathrm{kg})$ dissolved in $0.8 \mathrm{~mL}$ of PBS together with glucose $(3.8 \mathrm{~g} / \mathrm{kg}$ body weight). Blood samples were obtained via the tail vein at select time points after the intraperitoneal injection of glucose and the peptide. Glucose levels in the blood were measured with a OneTouch Ultra Blood Glucose Monitoring System and OneTouch Ultra Test Strips (Johnson and Johnson).

\section{Receptor-activation assay}

The expression vector for the human GIP receptor (Origene) was transfected into HEK293T cells using Lipofectamine 2000 (Invitrogen). Receptor-activation activities were assayed based on cAMP production in transfected cells and were performed as described (Park et al. 2008; Chang et al. 2010). To quantify resistance to serum degradation by GIP isoforms, aliquots of GIP peptides were incubated in microfuges at $37^{\circ} \mathrm{C}$ with human serum in a final concentration of $10 \mu \mathrm{M}$ for indicated time spans. To analyze the mechanism underlying the serum-degradation-resistant property of GIP55, peptides $(10 \mu \mathrm{M})$ were preincubated with a recombinant human DPP IV ( $1 \mathrm{mU} / \mathrm{mL}$ reaction in PBS; Enzo Life Science) for 3,6 , or $12 \mathrm{~h}$ and were frozen at $-80^{\circ} \mathrm{C}$ before being tested for receptor-activation activity. The receptor-activation results were analyzed using the GraphPad Prism 5 package (GraphPad Software).

\section{Acknowledgments}

We thank Yi Wei and Augustin Sanchez (Stanford University Pan Facility) for technical assistance. We thank Drs. Aaron J.W. Hsueh and Renee A. Reijo Pera (Department of OB/GYN, Stanford University) for the critical review of the manuscript, and C.L.C. further thanks Dr. Yung-Kuei Soong (Department of OB/GYN, Chang Gung Memorial Hospital, Taiwan). J.J.C. thanks Dr. Dmitri Petrov (Dept. of Biology, Stanford University) for his invaluable advice and long-lasting support. We acknowledge the support of $\mathrm{NIH}$ (DK70652, SYTH), Avon Foundation (02-2009-054, SYTH), and Chang Gung Memorial Hospital (CMRPG391151, CLC).

Author contributions: S.Y.T.H. conceived and supervised the study. C.L.C., J.P., and S.Y.T.H. were involved in functional testing and data analyses. J.J.C., C.L., and J.A. processed and performed genome data analyses. The paper was written primarily by C.L.C., J.J.C., and S.Y.T.H.

\section{References}

Akey JM. 2009. Constructing genomic maps of positive selection in humans: Where do we go from here? Genome Res 19: 711-722.

Akey JM, Zhang G, Zhang K, Jin L, Shriver MD. 2002. Interrogating a highdensity SNP map for signatures of natural selection. Genome Res 12: 1805-1814.

Allison AC. 1956. The sickle-cell and haemoglobin C genes in some African populations. Ann Hum Genet 21: 67-89.

Amigo J, Salas A, Phillips C, Carracedo A. 2008. SPSmart: Adapting population based SNP genotype databases for fast and comprehensive web access. BMC Bioinformatics 9: 428 .

Anderson TM, vonHoldt BM, Candille SI, Musiani M, Greco C, Stahler DR, Smith DW, Padhukasahasram B, Randi E, Leonard JA, et al. 2009. Molecular and evolutionary history of melanism in North American gray wolves. Science 323: 1339-1343.

Anonymous. 1989. Thrifty genotype rendered detrimental by progress? Lancet 2: 839-840.

Balter M. 2007. Plant science. Seeking agriculture's ancient roots. Science 316: $1830-1835$.

Barreiro LB, Quintana-Murci L. 2010. From evolutionary genetics to human immunology: How selection shapes host defence genes. Nat Rev Genet 11: $17-30$.

Barreiro LB, Laval G, Quach H, Patin E, Quintana-Murci L. 2008. Natural selection has driven population differentiation in modern humans. Nat Genet 40: $340-345$

Barrett JC, Fry B, Maller J, Daly MJ. 2005. Haploview: Analysis and visualization of LD and haplotype maps. Bioinformatics 21: 263-265.

Ben-Shlomo I, Yu Hsu S, Rauch R, Kowalski HW, Hsueh AJ. 2003. Signaling receptome: A genomic and evolutionary perspective of plasma membrane receptors involved in signal transduction. Sci STKE 203: RE9. doi: 10.1126/stke.2003.187.re9.

Broman KW, Murray JC, Sheffield VC, White RL, Weber JL. 1998. Comprehensive human genetic maps: Individual and sex-specific variation in recombination. Am J Hum Genet 63: 861-869.

Bryk J, Hardouin E, Pugach I, Hughes D, Strotmann R, Stoneking M, Myles S. 2008. Positive selection in East Asians for an EDAR allele that enhances NF-кB activation. PLOS ONE 3: е2209. doi: 10.1371/ journal.pone.0002209.

Buchanan TA, Xiang AH. 2005. Gestational diabetes mellitus. J Clin Invest 115: 485-491.

Cai JJ. 2008. PGEToolbox: A Matlab toolbox for population genetics and evolution. J Hered 99: 438-440.

Cai JJ, Macpherson JM, Sella G, Petrov DA. 2009. Pervasive hitchhiking at coding and regulatory sites in humans. PLoS Genet 5: e1000336. doi: 10.1371/journal.pgen.1000336.

Cann HM, de Toma C, Cazes L, Legrand MF, Morel V, Piouffre L, Bodmer J, Bodmer WF, Bonne-Tamir B, Cambon-Thomsen A, et al. 2002. A human genome diversity cell line panel. Science 296: 261-262.

Chambers JC, Elliott P, Zabaneh D, Zhang W, Li Y, Froguel P, Balding D, Scott J, Kooner JS. 2008. Common genetic variation near MC4R is associated with waist circumference and insulin resistance. Nat Genet 40: $716-718$

Chang CL, Park J-I, Hsu SYT. 2010. Activation of calcitonin receptor and calcitonin receptor-like receptor by membrane-anchored ligands. J Biol Chem 285: 1075-1080.

Charlesworth D. 2006. Balancing selection and its effects on sequences in nearby genome regions. PLoS Genet 2: e64. doi: 10.1371/ journal.pgen.0020064.

Chen H, Patterson N, Reich D. 2010. Population differentiation as a test for selective sweeps. Genome Res 20: 393-402.

Chia CW, Carlson OD, Kim W, Shin YK, Charles CP, Kim HS, Melvin DL, Egan JM. 2009. Exogenous glucose-dependent insulinotropic polypeptide worsens post prandial hyperglycemia in type 2 diabetes. Diabetes 58: 1342-1349. 
Clark AG, Wang X, Matise T. 2010. Contrasting methods of quantifying fine structure of human recombination. Annu Rev Genomics Hum Genet 11: 45-64.

Darwin C. 1859. On the origin of species by means of natural selection, or the preservation of favoured races in the struggle for life. John Murray, London.

Dib C, Faure S, Fizames C, Samson D, Drouot N, Vignal A, Millasseau P, Marc S, Hazan J, Seboun E, et al. 1996. A comprehensive genetic map of the human genome based on 5,264 microsatellites. Nature 380: 152-154.

Drews J. 2000. Drug discovery: A historical perspective. Science 287: 19601964.

Freeman S, Herron JC. 2003. Evolutionary analysis, 3rd ed. Prentice-Hall, Upper Saddle River, NJ.

Fujimoto A, Kimura R, Ohashi J, Omi K, Yuliwulandari R, Batubara L, Mustofa MS, Samakkarn U, Settheetham-Ishida W, Ishida T, et al. 2008. A scan for genetic determinants of human hair morphology: EDAR is associated with Asian hair thickness. Hum Mol Genet 17: 835-843.

Fuller DQ, Qin L, Zheng Y, Zhao Z, Chen X, Hosoya LA, Sun GP. 2009. The domestication process and domestication rate in rice: Spikelet bases from the Lower Yangtze. Science 323: 1607-1610.

Fulurija A, Lutz TA, Sladko K, Osto M, Wielinga PY, Bachmann MF, Saudan P. 2008. Vaccination against GIP for the treatment of obesity. PLoS ONE 3: e3163. doi: 10.1371/journal.pone.0003163.

Genovese G, Friedman DJ, Ross MD, Lecordier L, Uzureau P, Freedman BI, Bowden DW, Langefeld CD, Oleksyk TK, Uscinski Knob AL, et al. 2010. Association of trypanolytic ApoL1 variants with kidney disease in African Americans. Science 329: 841-845.

Gibbons A. 2010. Human evolution. Tracing evolution's recent fingerprints. Science 329: 740-742.

Gniuli D, Calcagno A, Dalla Libera L, Calvani R, Leccesi L, Caristo ME, Vettor R, Castagneto M, Ghirlanda G, Mingrone G. 2010. High-fat feeding stimulates endocrine, glucose-dependent insulinotropic polypeptide (GIP)-expressing cell hyperplasia in the duodenum of Wistar rats. Diabetologia 53: 2233-2240.

Gutenkunst RN, Hernandez RD, Williamson SH, Bustamante CD. 2009. Inferring the joint demographic history of multiple populations from multidimensional SNP frequency data. PLoS Genet 5: e1000695. doi: 10.1371/journal.pgen.1000695.

Hellenthal G, Stephens M. 2007. msHOT: Modifying Hudson's ms simulator to incorporate crossover and gene conversion hotspots. Bioinformatics 23: $520-521$.

Hoekstra HE, Hirschmann RJ, Bundey RA, Insel PA, Crossland JP. 2006. A single amino acid mutation contributes to adaptive beach mouse color pattern. Science 313: 101-104.

Hudson RR. 2002. Generating samples under a Wright-Fisher neutral model of genetic variation. Bioinformatics 18: $337-338$.

Ingelsson E, Langenberg C, Hivert MF, Prokopenko I, Lyssenko V, Dupuis J, Magi R, Sharp S, Jackson AU, Assimes TL, et al. 2010. Detailed physiologic characterization reveals diverse mechanisms for novel genetic Loci regulating glucose and insulin metabolism in humans. Diabetes 59: 1266-1275.

International HapMap Consortium. 2007. A second generation human haplotype map of over 3.1 million SNPs. Nature 449: 851-861.

International HapMap Project. 2003. The International HapMap Project. Nature 426: 789-796.

Isken F, Pfeiffer AF, Nogueiras R, Osterhoff MA, Ristow M, Thorens B, Tschop MH, Weickert MO. 2008. Deficiency of glucose-dependent insulinotropic polypeptide receptor prevents ovariectomy-induced obesity in mice. Am J Physiol Endocrinol Metab 295: E350-E355.

Itan Y, Powell A, Beaumont MA, Burger J, Thomas MG. 2009. The origins of lactase persistence in Europe. PLoS Comput Biol 5: e1000491. doi: 10.1371/journal.pcbi.1000491.

Jones MK, Liu X. 2009. Archaeology. Origins of agriculture in East Asia. Science 324: 730-731.

Kelley JL, Madeoy J, Calhoun JC, Swanson W, Akey JM. 2006. Genomic signatures of positive selection in humans and the limits of outlier approaches. Genome Res 16: 980-989.

Kim W, Egan JM. 2008. The role of incretins in glucose homeostasis and diabetes treatment. Pharmacol Rev 60: 470-512.

Kimura M, Ota T. 1973. The age of a neutral mutant persisting in a finite population. Genetics 75: 199-212.

Klein RG. 2009. Darwin and the recent African origin of modern humans. Proc Natl Acad Sci 106: 16007-16009.

Kong A, Gudbjartsson DF, Sainz J, Jonsdottir GM, Gudjonsson SA, Richardsson B, Sigurdardottir S, Barnard J, Hallbeck B, Masson G, et al. 2002. A high-resolution recombination map of the human genome. Nat Genet 31: 241-247.

Laland KN, Odling-Smee J, Myles S. 2010. How culture shaped the human genome: Bringing genetics and the human sciences together. Nat Rev Genet 11: 137-148.

Lalueza-Fox C, Rompler H, Caramelli D, Staubert C, Catalano G, Hughes D, Rohland N, Pilli E, Longo L, Condemi S, et al. 2007. A melanocortin 1 receptor allele suggests varying pigmentation among Neanderthals Science 318: 1453-1455.

Leslie M. 2010. Genetics. Kidney disease is parasite-slaying protein's downside. Science 329: 263.

Lewontin RC, Krakauer J. 1973. Distribution of gene frequency as a test of the theory of the selective neutrality of polymorphisms. Genetics 74: 175-195.

Li JZ, Absher DM, Tang H, Southwick AM, Casto AM, Ramachandran S, Cann HM, Barsh GS, Feldman M, Cavalli-Sforza LL, et al. 2008. Worldwide human relationships inferred from genome-wide patterns of variation. Science 319: 1100-1104.

Luca F, Perry GH, di Rienzo A. 2010. Evolutionary adaptations to dietary changes. Annu Rev Nutr 30: 291-314.

Ma RC, Chan JC. 2009. Pregnancy and diabetes scenario around the world: China. Int J Gynaecol Obstet 104: S42-S45.

McClean PL, Irwin N, Cassidy RS, Holst JJ, Gault VA, Flatt PR. 2007. GIP receptor antagonism reverses obesity, insulin resistance, and associated metabolic disturbances induced in mice by prolonged consumption of high-fat diet. Am J Physiol Endocrinol Metab 293: E1746-E1755.

McDougall I, Brown FH, Fleagle JG. 2005. Stratigraphic placement and age of modern humans from Kibish, Ethiopia. Nature 433: 733-736.

McVean GA, Myers SR, Hunt S, Deloukas P, Bentley DR, Donnelly P. 2004. The fine-scale structure of recombination rate variation in the human genome. Science 304: 581-584.

Miller JC, Colagiuri S. 1994. The carnivore connection: Dietary carbohydrate in the evolution of NIDDM. Diabetologia 37: 1280-1286.

Miyawaki K, Yamada Y, Ban N, Ihara Y, Tsukiyama K, Zhou H, Fujimoto S, Oku A, Tsuda K, Toyokuni S, et al. 2002. Inhibition of gastric inhibitory polypeptide signaling prevents obesity. Nat Med 8: 738-742.

Moody AJ, Thim L, Valverde I. 1984. The isolation and sequencing of human gastric inhibitory peptide (GIP). FEBS Lett 172: 142-148.

Neel JV. 1962. Diabetes mellitus: A "thrifty" genotype rendered detrimental by "progress"? Am J Hum Genet 14: 353-362.

Nei M, Suzuki Y, Nozawa M. 2010. The neutral theory of molecular evolution in the genomic era. Annu Rev Genomics Hum Genet 11: 265-289.

$\mathrm{Ng}$ SB, Bigham AW, Buckingham KJ, Hannibal MC, McMillin MJ, Gildersleeve HI, Beck AE, Tabor HK, Cooper GM, Mefford HC, et al. 2010. Exome sequencing identifies MLL2 mutations as a cause of Kabuki syndrome. Nat Genet 42: 790-793.

Nielsen R, Hellmann I, Hubisz M, Bustamante C, Clark AG. 2007. Recent and ongoing selection in the human genome. Nat Rev Genet 8: 857-868

Nystrom MJ, Caughey AB, Lyell DJ, Druzin ML, El-Sayed YY. 2008. Perinata outcomes among Asian-white interracial couples. Am J Obstet Gynecol 199: 385. doi: 10.1016/j.ajog.2008.06.065.

Park JI, Semyonov J, Chang CL, Yi W, Warren W, Hsu SY. 2008. Origin of INSL3-mediated testicular descent in therian mammals. Genome Res 18: 974-985.

Perry GH, Dominy NJ, Claw KG, Lee AS, Fiegler H, Redon R, Werner J, Villanea FA, Mountain JL, Misra R, et al. 2007. Diet and the evolution of human amylase gene copy number variation. Nat Genet 39: 1256-1260.

Pickrell JK, Coop G, Novembre J, Kudaravalli S, Li JZ, Absher D, Srinivasan BS, Barsh GS, Myers RM, Feldman MW, et al. 2009. Signals of recent positive selection in a worldwide sample of human populations. Genome Res 19: 826-837.

Piperno DR, Weiss E, Holst I, Nadel D. 2004. Processing of wild cereal grains in the Upper Palaeolithic revealed by starch grain analysis. Nature 430: 670-673.

Prentice AM, Rayco-Solon P, Moore SE. 2005. Insights from the developing world: Thrifty genotypes and thrifty phenotypes. Proc Nutr Soc 64: 153161.

Pritchard JK, Pickrell JK, Coop G. 2010. The genetics of human adaptation: Hard sweeps, soft sweeps, and polygenic adaptation. Curr Biol 20: R208R215.

Prokopenko I, McCarthy MI, Lindgren CM. 2008. Type 2 diabetes: New genes, new understanding. Trends Genet 24: 613-621.

Reich DE. 1998. Estimating the age of mutations using variation at linked markers. In Microsatellites: Evolution and applications, pp. 129-138. Oxford University Press, Oxford.

Reich DE, Goldstein DB. 1999. Estimating the age of mutations using variation at linked markers. In Microsatellites: Evolution and applications, (ed. DB Goldstein and C Schlotterer), pp. 129-138. Oxford University Press, Oxford.

Retnakaran R, Hanley AJ, Connelly PW, Sermer M, Zinman B. 2006. Ethnicity modifies the effect of obesity on insulin resistance in pregnancy: A comparison of Asian, South Asian, and Caucasian women. J Clin Endocrinol Metab 91: 93-97.

Richards MP, Trinkaus E. 2009. Out of Africa: Modern human origins special feature: Isotopic evidence for the diets of European Neanderthals and early modern humans. Proc Natl Acad Sci 106: 16034-16039.

Richerson PJ, Boyd R, Henrich J. 2010. Colloquium paper: Gene-culture coevolution in the age of genomics. Proc Natl Acad Sci 107: 8985-8992. 
Roach JC, Glusman G, Smit AF, Huff CD, Hubley R, Shannon PT, Rowen L, Pant KP, Goodman N, Bamshad M, et al. 2010. Analysis of genetic inheritance in a family quartet by whole-genome sequencing. Science 328: $636-639$.

Rosenberg NA. 2006. Standardized subsets of the HGDP-CEPH Human Genome Diversity Cell Line Panel, accounting for atypical and duplicated samples and pairs of close relatives. Ann Hum Genet 70: $841-847$.

Sabeti PC, Reich DE, Higgins JM, Levine HZ, Richter DJ, Schaffner SF, Gabriel SB, Platko JV, Patterson NJ, McDonald GJ, et al. 2002. Detecting recent positive selection in the human genome from haplotype structure. Nature 419: 832-837.

Sabeti PC, Walsh E, Schaffner SF, Varilly P, Fry B, Hutcheson HB, Cullen M, Mikkelsen TS, Roy J, Patterson N, et al. 2005. The case for selection at CCR5-Delta32. PLoS Biol 3: e378. doi: 10.1371/journal.pbio.0030378.

Sabeti PC, Varilly P, Fry B, Lohmueller J, Hostetter E, Cotsapas C, Xie X, Byrne EH, McCarroll SA, Gaudet R, et al. 2007. Genome-wide detection and characterization of positive selection in human populations. Nature 449: 913-918.

Saxena R, Hivert MF, Langenberg C, Tanaka T, Pankow JS, Vollenweider P, Lyssenko V, Bouatia-Naji N, Dupuis J, Jackson AU, et al. 2010. Genetic variation in GIPR influences the glucose and insulin responses to an oral glucose challenge. Nat Genet 42: 142-148.

Schluter D. 2000. The ecology of adaptive radiation. Oxford University Press, Oxford.

Seminara SB, Messager S, Chatzidaki EE, Thresher RR, Acierno JS Jr, Shagoury JK, Bo-Abbas Y, Kuohung W, Schwinof KM, Hendrick AG, et al. 2003. The GPR54 gene as a regulator of puberty. N Engl J Med 349: 1614-1627.

Semyonov J, Park JI, Chang CL, Hsu SY. 2008. GPCR genes are preferentially retained after whole genome duplication. PLOS ONE 3: e1903. doi: 10.1371/journal.pone.0001903.

Shiao MS, Liao BY, Long M, Yu HT. 2008. Adaptive evolution of the insulin two-gene system in mouse. Genetics 178: 1683-1691.

Shimomura Y, Wajid M, Ishii Y, Shapiro L, Petukhova L, Gordon D, Christiano AM. 2008. Disruption of P2RY5, an orphan G proteincoupled receptor, underlies autosomal recessive woolly hair. Nat Genet 40: $335-339$.

Simonson TS, Yang Y, Huff CD, Yun H, Qin G, Witherspoon DJ, Bai Z, Lorenzo FR, Xing J, Jorde LB, et al. 2010. Genetic evidence for highaltitude adaptation in Tibet. Science 329: 72-75.

Slatkin M, Rannala B. 2000. Estimating allele age. Annu Rev Genomics Hum Genet 1: 225-249.

Smith JM, Haigh J. 1974. The hitch-hiking effect of a favourable gene. Genet Res 23: 23-35.

Stephens JC, Reich DE, Goldstein DB, Shin HD, Smith MW, Carrington M, Winkler C, Huttley GA, Allikmets R, Schriml L, et al. 1998. Dating the origin of the CCR5-Delta32 AIDS-resistance allele by the coalescence of haplotypes. Am J Hum Genet 62: 1507-1515.

Sulem P, Gudbjartsson DF, Stacey SN, Helgason A, Rafnar T, Magnusson KP, Manolescu A, Karason A, Palsson A, Thorleifsson G, et al. 2007. Genetic determinants of hair, eye and skin pigmentation in Europeans. Nat Genet 39: 1443-1452.

Takeda J, Seino Y, Tanaka K, Fukumoto H, Kayano T, Takahashi H, Mitani T, Kurono M, Suzuki T, Tobe T, et al. 1987. Sequence of an intestinal cDNA encoding human gastric inhibitory polypeptide precursor. Proc Natl Acad Sci 84: 7005-7008.

Tishkoff SA, Reed FA, Ranciaro A, Voight BF, Babbitt CC, Silverman JS, Powell K, Mortensen HM, Hirbo JB, Osman M, et al. 2007. Convergent adaptation of human lactase persistence in Africa and Europe. Nat Genet 39: 31-40.

Topaloglu AK, Reimann F, Guclu M, Yalin AS, Kotan LD, Porter KM, Serin A, Mungan NO, Cook JR, Ozbek MN, et al. 2009. TAC3 and TACR3 mutations in familial hypogonadotropic hypogonadism reveal a key role for Neurokinin B in the central control of reproduction. Nat Genet 41: $354-358$.

Turner JR, Johnson MS, Eanes WF. 1979. Contrasted modes of evolution in the same genome: Allozymes and adaptive change in Heliconius. Proc Natl Acad Sci 76: 1924-1928.

Vander Molen J, Frisse LM, Fullerton SM, Qian Y, Del Bosque-Plata L, Hudson RR, Di Rienzo A. 2005. Population genetics of CAPN10 and GPR35: Implications for the evolution of type 2 diabetes variants. Am J Hum Genet 76: 548-560.

Voight BF, Kudaravalli S, Wen X, Pritchard JK. 2006. A map of recent positive selection in the human genome. PLoS Biol 4: e72. doi: 10.1371/ journal.pbio.0040072.

Voight BF, Scott LJ, Steinthorsdottir V, Morris AP, Dina C, Welch RP, Zeggini E, Huth C, Aulchenko YS, Thorleifsson G, et al. 2010. Twelve type 2 diabetes susceptibility loci identified through large-scale association analysis. Nat Genet 42: 579-589.

Wang ET, Kodama G, Baldi P, Moyzis RK. 2006. Global landscape of recent inferred Darwinian selection for Homo sapiens. Proc Natl Acad Sci 103: 135-140.

Weir BS. 1996. Genetic data analysis II: Methods for discrete population genetic data. Sinauer Associates, Sunderland.

Yi X, Liang Y, Huerta-Sanchez E, Jin X, Cuo ZX, Pool JE, Xu X, Jiang H, Vinckenbosch N, Korneliussen TS, et al. 2010. Sequencing of 50 human exomes reveals adaptation to high altitude. Science 329: 75-78.

Received May 17, 2010; accepted in revised form October 22, 2010.

\section{Genome Research




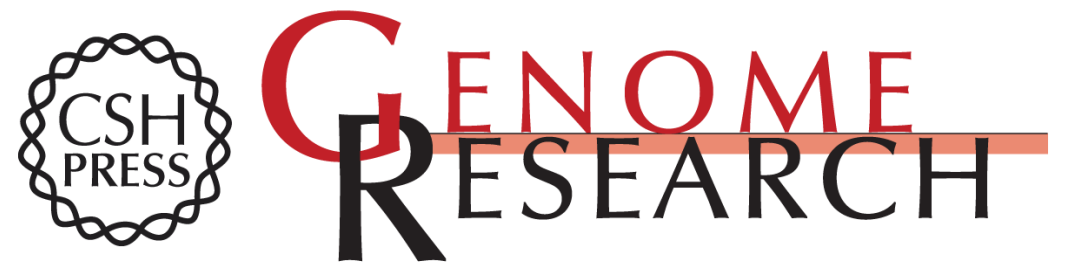

\section{Adaptive selection of an incretin gene in Eurasian populations}

Chia Lin Chang, James J. Cai, Chiening Lo, et al.

Genome Res. 2011 21: 21-32 originally published online October 26, 2010

Access the most recent version at doi:10.1101/gr.110593.110

\section{Supplemental http://genome.cshlp.org/content/suppl/2010/10/27/gr.110593.110.DC1 \\ Material}

References This article cites 98 articles, 31 of which can be accessed free at:

http://genome.cshlp.org/content/21/1/21.full.html\#ref-list-1

\section{License}

Email Alerting Receive free email alerts when new articles cite this article - sign up in the box at the Service top right corner of the article or click here.

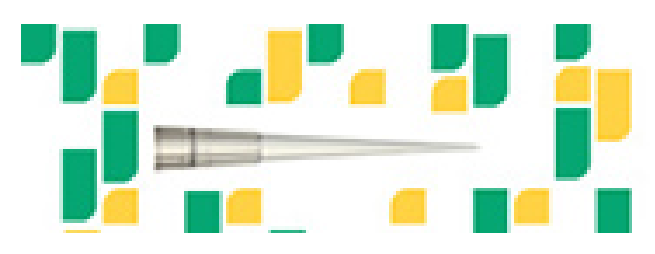

To subscribe to Genome Research go to: https://genome.cshlp.org/subscriptions 